\title{
Knowledge and perceptions on childhood asthma among care-takers of children with asthma at a National Referral Hospital in Western Kenya: a descriptive study
}

\author{
Justus Simba ${ }^{1}$, Irene Marete ${ }^{2}$, Rebecca Waihenya ${ }^{3}$, Yeri Kombe ${ }^{4}$, Ann Mwangi ${ }^{5}$, \\ Patrick Mburugu ${ }^{1}$, Francis Ogaro ${ }^{6}$
}

1. Jomo Kenyatta University of Agriculture and Technology, Child Health and Paediatrics.

2. Moi University School of Medicine, Child Health and Paediatrics.

3. Jomo Kenyatta University of Agriculture and Technology, Zoology.

4. Kenya Medical Research Institute.

5. Moi University School of Medicine, Behavioural Sciences.

6. Moi Teaching and Referral Hospital.

\begin{abstract}
Background: Identifying knowledge gaps in asthma self-management and identifying existing myths is an important step in determining appropriate health education and demystifying the myths so as to enhance asthma control.

Objective: To identify existing knowledge gaps and perceptions among the caregivers of asthmatic children.

Methods: A cross sectional study was done among caretakers of asthmatic children aged 6-11 years at Moi Teaching and Referral Hospital. Data on knowledge and perceptions among caretakers was collected using a questionnaire.

Results: A total of 116 caretakers were recruited of whom $71.6 \%$ were mothers. Although $60 \%$ of the caretakers had asthma medications at home, only a third felt their children were asthmatic. Eighty four $(72.4 \%)$ had basic asthma knowledge. Syrups were preferred to inhalers by $70.7 \%$, with $64.7 \%$ believing that inhalers were for the very sick. Only $36(31 \%)$ felt preventer medications in asthma were necessary. Acceptance of asthma as a diagnosis and presence of asthma drugs were significantly associated with better knowledge of asthma, p-values 0.015 and 0.009 respectively.

Conclusion: Most caregivers perceive syrups to be better despite having good basic knowledge on asthma. There is need to address asthma perceptions among caretakers in resource poor settings which is likely to improve control.
\end{abstract}

Keywords: Childhood asthma, care-takers, Western Kenya.

DOI: https://dx.doi.org/10.4314/ahs.v18i4.16

Cite as: Simba J, Marete I, Waihenya R, Kombe Y, Mwangi A, Mburugu P, Ogaro F. Knowledge and perceptions on childhood asthma among care-takers of children with asthma at a National Referral Hospital in Western Kenya: a descriptive study. Afri Health Sci. 2018;18(4): $965-971$. bttps://dx.doi.org/10.4314/abs.v18i4.16

\section{Background}

The mainstay of asthma management includes use of bronchodilators such as salbutamol and use of steroids mainly the inhaled ones. The intensity of the treatment chosen is mainly influenced by the severity ${ }^{1}$. These medications form the cornerstone of management ${ }^{2}$. There

\section{Corresponding author:}

Justus Simba, Jomo Kenyatta University of Agriculture and Technology, Child Health and Paediatrics

Email: maingij@gmail.com have been concerted efforts to ensure that these drugs are available so as to ease the individual's burden of asthma. Some evidence shows that the availability of these medications alone does not lead to good control ${ }^{3}$.

Many other factors influence the level of asthma control. Some of these factors are related to health workers while others relate to the caretakers of the children. Adherence to treatment is the single most important determinant of asthma control ${ }^{4}$. This however is affected by the parents' satisfaction with involvement in decision-making as well as perceived level of interaction with the health worker ${ }^{5}$. Similarly, low educational attainment, low income, cigarette smoking, co-morbid conditions including obesity

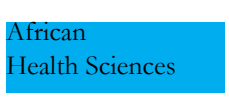

(C) 2018 Simba et al. Licensee African Health Sciences. This is an Open Access article distributed under the terms of the Creative commons Attribution License (https://creativecommons.org/licenses/BY/4.0), which permits unrestricted use, distribution, and reproduction in any medium, provided the original work is properly cited. 
and depression ${ }^{6}$, pet ownership, other allergic comorbid diseases, especially rhinitis ${ }^{7}$, weather seasonality (including pollination), occupation and food allergies ${ }^{8-10}$ have also been shown to affect control in asthmatics.

In low income countries, including Kenya, many children continue to visit hospitals with acute symptoms of asthma, which is a pointer to poor control. In a recent study in Nairobi and its environs, good control was reported as $42 \%$ among asthmatic children aged $1-14$ years $^{11}$. In addition to the factors highlighted above, the socio-economic factors have a great role in exacerbating asthma attacks. The level of acceptance of current care is affected by misconceptions and stigma associated with the management especially the use of inhalers ${ }^{12}$. We describe the myths, perceptions and knowledge on asthma among parents of children with asthma in a poor resource setting.

\section{Methods}

A cross-sectional study was carried out at the children's clinics of the Moi Teaching and Referral Hospital (MTRH), between August 2016 and December 2016. MTRH is a national referral hospital located in Eldoret serving the Western part of Kenya with a catchment population of approximately 15 million. Up to 3000 children are seen per month in this hospital. There are two specialized paediatric clinics per week which attend to an average of 100 children per month. Although there is a paediatric pulmonology clinic being set up, the numbers are still low. There are no asthma health educators and patient education is at the discretion of the attending clinician. No lung function tests are performed on children who are on management for asthma in this hospital.

Children aged 6-11 years attending the clinic at MTRH together with their parents/caretakers were enrolled into phase one, a cross sectional study, (subsequently enrolled into a second phase, a trial registration PACTR201702002061736) if they met diagnosis of asthma using ISAAC screening questionnaire and consent was given. We excluded children who were unstable or very sick (requiring urgent resuscitation measures such as oxygen, urgent rehydration, anti-convulsants) or succumbed to illness within 24 hours of screening. Similarly those with serious chronic comorbidities, for example, chronic heart failure as well as non-residents of Western Kenya were excluded.

All children presenting to the hospital aged 6-11 years were eligible for participation and were screened for suitability using a validated parent/caregiver screening questionnaire used originally in the ISAAC studies ${ }^{2,13-16}$. The questionnaire used for 6-7 year olds in the ISAAC studies was used. Children identified as asthmatic from the screening had data collected using a questionnaire which mainly looked for background variables as well as parental knowledge and beliefs concerning asthma treatment.

Data was entered into Microsoft Access. It was then exported to STATA Version13 for analysis. Descriptive statistics were generated from the baseline study. We assessed knowledge on asthma by scoring individual questions with 1 score for correct response and dichotomized to $\leq 9$ and $\geq 10$ as not knowledgeable and knowledgeable respectively. Attitude questions were individually scored. The Chi-square test was used to test for categorical variables association. Level of significance was set at 0.05 . Clearance to carry out the research was granted from the ethics review committee of MTRH/College of Health Sciences, Moi University. Enrolled participants gave informed consent.

\section{Results}

A total of 116 families took part. The median age of the children was 8.3 years. Most parental respondents were mothers $(n=83,71.6 \%)$ from urban settings $(n=85$, $73.3 \%$ ) who had attained at least secondary school education $(\mathrm{n}=109,94 \%)$. The results are summarised in Table 1.

Whilst self-reported asthma knowledge was high, with less than one-fifth of caregivers rating themselves as 'not knowledgeable' ( $n=23,19.8 \%$ ) just less than one third of respondents accepted that their child had asthma $(n=38$, $32.8 \%$ ). At least $50.9 \%$ perceived their child's illness to be well controlled and interestingly 66 (56.9\%), acknowledged that they had drugs at home to control their child's symptoms. This is shown in table 1. 
Table 1: Baseline cha racteristics of children/caretakers

\begin{tabular}{|c|c|c|}
\hline Variable & Freq & $\%$ \\
\hline Age of child in years & $\mathrm{n}=116$ & \\
\hline Median (IQR) & $8.33(7,10)$ & \\
\hline \multicolumn{3}{|l|}{ Gender of child } \\
\hline Male & 65 & $56.00 \%$ \\
\hline Female & 51 & $44.00 \%$ \\
\hline \multicolumn{3}{|l|}{ Relationship with child } \\
\hline Mother & 83 & $71.60 \%$ \\
\hline Father & 20 & $17.20 \%$ \\
\hline Other & 13 & $11.20 \%$ \\
\hline \multicolumn{3}{|l|}{ Residence } \\
\hline Urban & 85 & $73.30 \%$ \\
\hline Rural & 31 & $26.70 \%$ \\
\hline \multicolumn{3}{|l|}{ Season recruited } \\
\hline Wet & 65 & $56.00 \%$ \\
\hline Dry & 51 & $44.00 \%$ \\
\hline \multicolumn{3}{|c|}{ History of asthma in family } \\
\hline Yes & 72 & $62.10 \%$ \\
\hline No & 44 & $37.90 \%$ \\
\hline \multicolumn{3}{|c|}{ Highest education level of caretaker } \\
\hline None & 3 & $2.60 \%$ \\
\hline Primary & 4 & $3.40 \%$ \\
\hline Secondary & 21 & $18.10 \%$ \\
\hline Tertiary college & 43 & $37.10 \%$ \\
\hline University & 45 & $38.80 \%$ \\
\hline \multicolumn{3}{|c|}{ Asthma drugs at home for child } \\
\hline Yes & 66 & $56.90 \%$ \\
\hline No & 50 & $43.10 \%$ \\
\hline \multicolumn{3}{|c|}{ Health provider talked about asthma action plan } \\
\hline Yes & 30 & $25.90 \%$ \\
\hline No & 86 & $74.10 \%$ \\
\hline \multicolumn{3}{|c|}{ Caretaker perception on child's control level } \\
\hline Well controlled & 59 & $50.90 \%$ \\
\hline Partially controlled & 49 & $42.20 \%$ \\
\hline Poorly controlled & 8 & $6.90 \%$ \\
\hline \multicolumn{3}{|c|}{ Acceptance that child has asthma } \\
\hline Yes & 38 & $32.80 \%$ \\
\hline No & 78 & $67.20 \%$ \\
\hline \multicolumn{3}{|c|}{ Perceived knowledge on asthma } \\
\hline Knowledgeable & 43 & $37.10 \%$ \\
\hline Knows a little & 50 & $43.10 \%$ \\
\hline Not knowledgeable & 23 & $19.80 \%$ \\
\hline
\end{tabular}


When questions measuring knowledge on asthma among the caretakers were analysed, 84(72.4\%) were determined to be knowledgeable as they answered at least half of the questions correctly.

Generally the presentation of asthma was well identified. Breathlessness (difficulty in breathing) was the least identified as the presentation of asthma by 84 (72.41\%). Caretakers were able to identify correctly that chemicals with bad smell, 66 (56.9\%), cold air, 101 (87.07\%), and strong perfumes, $73(62.93 \%)$ trigger asthmatic attack. Few individuals were able to identify that emotional stress, 25 (21.55\%), exercise, $55(47.4 \%)$ and cockroaches $13(11.21 \%)$ and aspirin/ibuprofen, 11(9.48\%) trigger asthmatic attack. At least half, $50.86 \%$ of the participants were able to pick the correct definition of asthma. However, most participants were not able to identify the cause of asthma.

We subjected the caretakers to a set of questions to establish their perception on asthma treatment. Most of the caretakers preferred syrups for inhalers in the management of asthma. Specifically $72(62.1 \%)$ felt broncho dilatation is best achieved by syrups while only $34(29.3 \%)$ would prefer inhalers on their child given choice. Interestingly though, only 39 (33.6\%) feared inhalers. Concerning controller medications, only $36(31.0 \%)$ felt daily medications were necessary in asthma care. More than half $(55.2 \%)$ felt not enough information concerning their child's condition had been addressed by health care workers. This is shown in detail in table 2.

Table 2: Perceptions on asthma treatment by caretakers

\begin{tabular}{|c|c|c|}
\hline Variable & Freq & $\%$ \\
\hline \multicolumn{3}{|c|}{ Bronchodilator treatment is best achieved when given as: } \\
\hline Inhaler & 44 & $37.90 \%$ \\
\hline Syrup & 72 & $62.10 \%$ \\
\hline \multicolumn{3}{|c|}{ Given a choice ca re taker prefersinha ler over sy rup: } \\
\hline Yes & 34 & $29.30 \%$ \\
\hline No & 82 & $70.70 \%$ \\
\hline \multicolumn{3}{|c|}{ Believe that inhalers are for the seriously sick: } \\
\hline Yes & 75 & $64.70 \%$ \\
\hline No & 41 & $35.30 \%$ \\
\hline \multicolumn{3}{|c|}{ Fear inhaler as not approved by othe $r$ people: } \\
\hline Yes & 39 & $33.60 \%$ \\
\hline No & 77 & $66.40 \%$ \\
\hline \multicolumn{3}{|c|}{ No need of daily drugs, given with wheezing } \\
\hline Yes & 80 & $69.00 \%$ \\
\hline No & 36 & $31.00 \%$ \\
\hline \multicolumn{3}{|c|}{ Child 6-11 years requires a spacer to use inhalers: } \\
\hline Yes & 54 & $46.60 \%$ \\
\hline No & 62 & $53.40 \%$ \\
\hline \multicolumn{3}{|c|}{ Feeling enough information concerning child } \\
\hline Yes & 52 & $44.80 \%$ \\
\hline No & 64 & $55.20 \%$ \\
\hline \multicolumn{3}{|c|}{ Concerns/fears addressed by health workers: } \\
\hline Yes & 60 & $51.70 \%$ \\
\hline No & 56 & $48.30 \%$ \\
\hline
\end{tabular}


On determining whether there are any predictors of knowledge from the baseline characteristics, acceptance that child has asthma and acknowledgement that there were drugs at home to help with attacks were positively associated with being knowledgeable at $\mathrm{p}$ value of 0.015 and 0.009 respectively. This is shown in detail in table 3 .

Table 3: Association between caretaker's baseline characteristics and knowledge

Variable

Gender of child

Male

Female

Relationship to child

Mother

Father

Other

Residence

Urban

Rural

Season recruited

Wet

Dry

History of asthma in family

Yes

No

Education level of caretaker

None

Primary

Secondary

Tertiary college

University

Drug at home to relieve attack

Yes

No

Talk about asthma action plan

Yes

No

Recurrent wheezing

Well controlled

Partially controlled

Poorly controlled

Acceptance child has asthma

Yes

No

Caretaker knowledge on asthma

Knowledgeable

Knows a little

Not knowledgeable
Knowledgeable

No

$15(23.1)$

$17(33.3)$

$25(30.1)$

$3(15)$

$4(30.8)$

$25(29.4)$

7 (22.6)

$11(16.9)$

$21(41.2)$

$17(23.6)$

$15(34.1)$

$0(0)$

$0(0)$

8 (38.1)

$11(25.6)$

13 (28.9)

12 (18.2)

20 (40)

7 (23.3)

$25(29.1)$

$16(27.1)$

15 (30.6)

1 (12.5)

5 (13.2)

27 (34.6)

7 (16.3)

19 (38)

$6(26.1)$ p-value

Yes

50 (76.9)

0.22

34 (66.7)

58 (69.9)

0.383

17 (85)

9 (69.2)

60 (70.6)

0.466

24 (77.4)

$54(83.1)$

$30(58.8)$

0.004

55 (76.4)

0.22

29 (65.9)

3 (100)

0.412

4 (100)

13 (61.9)

32 (74.4)

32 (71.1)

54 (81.8)

0.009

30 (60)

23 (76.7)

0.545

61 (70.9)

43 (72.9)

0.565

34 (69.4)

7 (87.5)

33 (86.8)

0.015

51 (65.4)

36 (83.7)

0.064

17 (73.9)

\section{Discussion}

Our analysis of this cohort of caretakers shows that the level of knowledge was fairly high with $72.4 \%$ answering more than half of the questions correctly. In a large study from China, $51.34 \%$ of the parents scored less than half for the questions assessed ${ }^{17}$. In Egypt, Tantawi H. et.al 
recorded a pre-intervention knowledge of $18.75 \%{ }^{18}$. Our populations had $94 \%$ of the participants having attained secondary education. This could partially be responsible for the high level of knowledge. Our study again was carried out in a largely urban set up and included both the private wing and the general wing of the hospital. The private wing of the MTRH is the one where hospital staff and their dependents are attended to. This could have an influence as most of the staff are health workers.

Although inhalers are advocated world over, our study shows that the parents/guardians preferred using syrups for their children. We assessed for this perception by asking three different questions which had similar results. While several possibilities could be responsible for this, it shows that the challenges in different regions may differ as it pertains asthma care. While this same group appeared knowledgeable, they prefer syrups which are associated with more side effects and are less effective. Similarly, although preventer medications which are given daily are the cornerstone of asthma medications ${ }^{2}$, only $69 \%$ of our study participants felt they were necessary. This could mean we have unmet needs both for the parents and health workers which have been shown can occur in different cultures/ regions ${ }^{19}$.

Among other things, WHO has identified that ability to describe correctly asthma treatment is one of the pre-requisites for effective asthma care ${ }^{20}$. For patients to have proper knowledge, asthma education is important. It has to be actively provided ${ }^{21}$. The questions this raises are we attempting to focus on the patients while the bigger gap might be with the health workers? In our sample, only about half of the participants were satisfied with the information they received from the health workers. There is evidence that better control is associated with perceived satisfaction by the patients/ care takers ${ }^{5}$. It is with this in mind that these results at a national referral hospital, which is home to one of the best medical schools in the region should be worrisome. Are we doing enough as far as basic education to health workers who see children with the possibility of asthma is concerned?

On testing for association of knowledge and selected baseline characteristics, having reliever medications as well as acceptance that child had asthma by the parents/ caretaker was associated with better knowledge of asthma. This might mean that health workers need to take up the mantle of educating care takers of children with asthma on the disease. There is widespread concern that asthma stigma is worsened by the health workers as they do not attempt to tell a patient that they could be having asthma. Although there is no asthma registry at this hospital, when we screened children who came hospital for whatever reason, at least $10 \%$ met the criteria using the ISAAC questionnaire that they were suffering from asthma. However, a good number either were not aware or did not acknowledge that their child had asthma. Only $32 \%$ of the parents/caretakers felt their child had asthma. The physician's diagnosis of asthma to a child has been shown to a be strong determinant of asthma treatment ${ }^{22}$. When a child has not received a diagnosis of asthma, they are less likely to be on any asthma medications. In our study, we found that $56 \%$ said they had a medication at home to relieve attacks. This is higher than the $9 \%$ that Maziak et.al found. However, our number included unacceptable medications like syrups. While other studies have found that education level is a main determinant of level of knowledge ${ }^{17}$, we did not find this association. Notable however, is that, in our cohort a small minority $(6 \%)$ had lower level of education.

\section{Conclusion}

While inhalers have been shown to work and are advocated for by national and international guidelines, most caregivers perceive syrups to be better. This is despite having good basic knowledge on asthma. This study provides evidence that there is need to address asthma perceptions among parents/caretakers in resource poor setting which is likely to improve control.

\section{Acknowledgement}

JMS received funds from Jomo Kenyatta University of Agriculture and Technology, Kenya as part of staff development as well as from National Research FundKenya for postgraduate students 2016/2017 to support this research. We wish also to acknowledge the Director of MTRH for giving permission to have this study carried out in the institution. The study research assistants who gave their time in ensuring data collection went on smoothly we are indebted. Lastly, all the parents/caretakers and children who participated in this research are appreciated.

\section{Conflict of interest}

The authors declare no conflict of interest.

African Health Sciences Vol 18 Issue 4, December, 2018 


\section{References}

1. Taylor D, Bateman E, Boulet L, Boushey H, Busse W, Casale T, Chanez P, Enright P, Gibson P, De Jongste J: A new perspective on concepts of asthma severity and control. European Respiratory Journal. 2008, 32(3):545-554. doi:10.1183/09031936.00155307

2. Network GA: The Global Asthma Report 2014. Auckland, New Zealand 2014.

3. Mash B, Rhode H, Pather M, Ainslie G, Irusen E, Bheekie A, Mayers P: Quality of asthma care: Western Cape Province, South Africa. SAMJ: South African Medical Journal. 2009, 99(12):892-896.

4. Klok T, Kaptein AA, Duiverman EJ, Brand PL: It's the adherence, stupid (that determines asthma control in preschool children)! European Respiratory Journal. 2014, 43(3):783-791.doi: 10.1183/09031936.00054613

5. Gandhi PK, Kenzik KM, Thompson LA, DeWalt DA, Revicki DA, Shenkman EA, Huang I-C: Exploring factors influencing asthma control and asthma-specific health-related quality of life among children. Respir Res. 2013, 14(1):26.doi:10.1186/1465-9921-14-26

6. Zahran HS, Bailey CM, Qin X, Moorman JE: Assessing asthma control and associated risk factors among persons with current asthma-findings from the child and adult Asthma Call-back Survey. Journal of Asthma. 2015, 52(3):318-326.doi: 10.3109/02770903.2014.956894

7. Sasaki M, Yoshida K, Adachi Y, Furukawa M, Itazawa T, Odajima H, Saito H, Akasawa A: Factors associated with asthma control in children: findings from a national Web-based survey. Pediatric Allergy and Immunology. 2014, 25(8):804-809.doi:10.1111/pai.12316

8. WHO: World Health Organization. Asthma fact sheet No. 307. Updated November 2013. Availablefrom: http://wwwwhoint/topics/asthma/es2008.

9. Mireku N, Wang Y, Ager J, Reddy RC, Baptist AP: Changes in weather and the effects on pediatric asthma exacerbations. Annals of Allergy, Asthma \& Immunology. 2009, 103(3):220-224.doi:10.1016/S1081-1206(10)601858

10. Kewalramani A, Bollinger ME: The impact of food allergy on asthma. Journal of Asthma and Allergy. 2010, 3:65.

11. Kigathi B: Factors affecting levels of Asthma control in patients presenting to Kenyatta National, Thika and Mbagathi Districts Hospital. University of Nairobi, Kenya; 2012.
12. Global strategy for asthma management and prevention www.ginasthma.org

13. Manual IPO: December 1993. In.: Auckland (NZ): Munster (FRG); 1993.

14. Ellwood P, Asher M, Beasley R, Clayton T, Stewart A, Committee IS: The International Study of Asthma and Allergies in Childhood (ISAAC): Phase Three rationale and methods Research Methods. The International Journal of Tuberculosis and Lung Disease. 2005, 9(1):10-16.

15. van Gemert F, van der Molen T, Jones R, Chavannes $\mathrm{N}$ : The impact of asthma and COPD in sub-Saharan Africa. Prim Care Respir J. 2011, 20(3):240-248.doi:10.4104/ pcrj.2011.00027

16. Adeloye D, Chan KY, Rudan I, Campbell H: An estimate of asthma prevalence in Africa: a systematic analysis. Croatian Medical Journal. 2013, 54(6):519-531. doi: $10.3325 \% 2$ Fcmj.2013.54.519

17. Zhao J, Shen K, Xiang L, Zhang G, Xie M, Bai J, Chen Q: The knowledge, attitudes and practices of parents of children with asthma in 29 cities of China: a multi-center study. BMC Pediatrics. 2013, 13(1):20.doi: 10.1186/14712431-13-20

18. Tantawi H, Adly R, Fathy Z: Effect of Educational Guidelines Program on Asthmatic Children and their Mothers. Journal of American Science. 2012, 8(10).

19. Lalloo U, Walters R, Adachi M, De Guia T, Emelyanov A, Fritscher C, Hong J, Jimenez C, King G, Lin $\mathrm{J}$ : Asthma programmes in diverse regions of the world: challenges, successes and lessons learnt. The International Journal of Tuberculosis and Lung Disease. 2011, 15(12):15741587.doi: 10.5588/ijtld.11.0289

20. Partridge M, Hill S: Enhancing care for people with asthma: the role of communication, education, training and self-management. 1998 World Asthma Meeting Education and Delivery of Care Working Group. European Respiratory Journal. 2000, 16(2):333-348.

21. Guevara JP, Wolf FM, Grum CM, Clark NM: Effects of educational interventions for self management of asthma in children and adolescents: systematic review and meta-analysis. BMJ. 2003, 326(7402):1308-1309. doi:10.1136/bmj.326.7402.1308

22. Maziak W, Von Mutius E, Beimfohr C, Hirsch T, Leupold W, Keil U, Weiland S: The management of childhood asthmain the community. European Respiratory Journal.2002, 20(6):1476-1482.doi: 10.1183/09031936.02.00281102 